\title{
Call for Special Issue Papers: Oncolytic Viruses and Cancer Immunotherapy
}

\author{
Deadline for Manuscript Submission: October 15, 2020
}

Guest Editor: Prem Seth; Director, Gene Therapy Program at North Shore University Health System

In recent years, there has been significant progress in the development of novel cancer immunotherapies including immune checkpoint blockade (ICB) therapy, chimeric antigen receptor T cells (CAR-T) therapy, adoptive cell mediated therapy, tumor vaccines and the development of bispecific $T$ cell engager (BiTE) antibodies. Despite these advances, a majority of cancer patients respond poorly to immunotherapies indicating a tremendous need to improve this treatment approach. Novel oncolytic viruses can produce selective tumor cell killing and can be genetically manipulated to induce antitumor immune responses that are beneficial in treatment and are nonredundant and even synergistic to other immunotherapies. These findings provide evidence that combination immunotherapies may result in better clinical outcomes than mono-therapies alone. Human Gene Therapy is now seeking original papers and review articles that describe innovative combination therapies to enhance cancer immunotherapy in the preclinical as well clinical setting. The design, optimization, and application of such therapies,

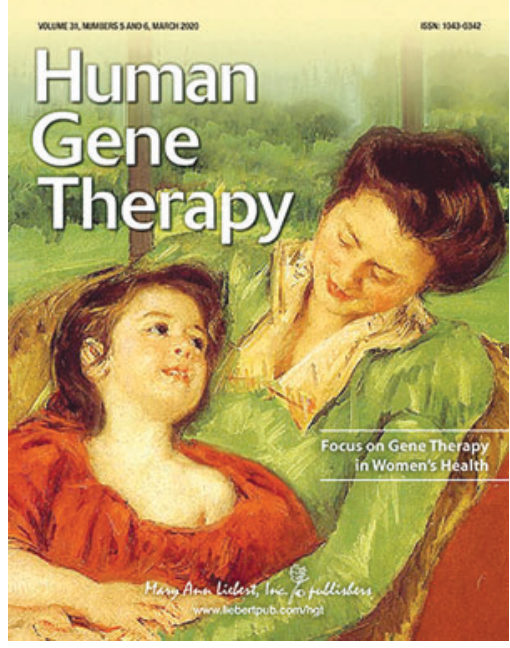
including, but not limited to, the following technologies are sought:

- Oncolytic viruses

- immune checkpoint blockade therapy

- CAR-T therapy

- Cancer vaccines

- Antibody based targeted therapies

- Bispecific antibodies including BiTE

- Adoptive cell transfer (ACT) therapy

- Other immunotherapies, and standard cancer therapies

\section{Visit the Instructions for Authors: www.liebertpub.com/HGT}

\section{Submit your paper for peer review online: https://mc.manuscriptcentral.com/hum}

Mary Ann Liebert, Inc., publishers, 140 Huguenot Street, New Rochelle, NY 10801, USA. 